\title{
Previdência social e desenvolvimento socioeconômico: impactos nos municípios de pequeno porte de Minas Gerais*
}

\author{
Paulo Ricardo da Costa Reis \\ Universidade Federal de Viçosa / Universidade Federal da Bahia \\ Suely de Fátima Ramos Silveira \\ Universidade Federal de Viçosa \\ Marcelo José Braga \\ Universidade Federal de Viçosa
}

\begin{abstract}
Em face da importância da previdência social na arena das políticas públicas sociais brasileiras, principalmente nos municípios de pequeno porte, o objetivo principal deste artigo consistiu na avaliação do impacto dos benefícios emitidos pela previdência social sobre a eficiência na promoção do desenvolvimento socioeconômico entre os pequenos municípios do estado de Minas Gerais. Para tanto, utilizou-se a técnica de análise envoltória dos dados em dois estágios. Os resultados da pesquisa permitiram concluir que os benefícios pagos pela previdência social impactaram, positivamente, a eficiência municipal na promoção do desenvolvimento socioeconômico.
\end{abstract}

Palavras-chave: previdência social; pequenos municípios; eficiência; desenvolvimento socioeconômico.

Previsión social y desarrollo socioeconómico: impactos en municipios pequeños de Minas Gerais Reconociendo la importancia de la seguridad social junto a las políticas públicas sociales brasileñas, principalmente para los pequeños municipios, el objetivo principal de este artículo fue la evaluación del impacto de los beneficios emitidos por la seguridad social sobre la eficiencia en la promoción del desarrollo socioeconómico entre los pequeños municipios de Minas Gerais. Para tanto, el estudio hice uso de la técnica del análisis envolvente de datos en dos etapas. Los resultados de la investigación permitieron concluir que los beneficios pagos por la seguridad social impactaron positivamente la eficiencia municipal en la promoción del desarrollo socioeconómico.

Palabras clave: previsión social; pequeños municipios; eficiencia; desarrollo socioeconómico.

Artigo recebido em 6 jul. 2012 e aceito em 18 fev. 2013.

* Os autores agradecem à Capes e ao CNPq pelo financiamento e incentivo à pesquisa. 


\begin{abstract}
Social security and socioeconomic development: Impacts on the small municipalities of Minas Gerais

Recognizing the importance of social security in the arena of Brazilian social policies, especially for small municipalities, the main objective of this paper was to evaluate the impact of social security benefits on efficiency in promoting socioeconomic development among small municipalities in the state of Minas Gerais. Thus, the study uses the technique of data envelopment analysis in two stages. The survey results showed that the benefits paid by social security had a positive effect in the promotion the efficiency of municipal socioeconomic development.
\end{abstract}

KEYwORDs: social security; small municipalities; efficiency; socioeconomic development.

\title{
1. Introdução
}

Desde a década de 1930, a política pública de previdência social brasileira destaca-se como uma das principais políticas públicas na área social, tendo como principal objetivo assegurar a renda dos trabalhadores e seus familiares em casos de perda da sua capacidade de trabalho. O sistema previdenciário brasileiro é caracterizado como sistema de repartição simples, semelhante àquele de países como Alemanha, França, Japão e Estados Unidos, em que os mais jovens (contribuintes atuais) financiam os mais velhos (aposentados e pensionistas).

O sistema brasileiro divide-se basicamente em dois subsistemas. O primeiro subsistema corresponde à Previdência Social básica, oferecida pelo poder público e constituída tanto pelos Regimes Próprios de Previdência Social (RPPS), que são responsáveis pelos trabalhadores do setor público, quanto pelo Regime Geral de Previdência Social (RGPS), que é destinado aos trabalhadores do setor privado. O segundo subsistema, cujo caráter é facultativo e complementar ao regime de previdência oficial, corresponde à Previdência Privada, sendo constituído pelas Empresas Abertas de Previdência Complementar (EAPC) e pelas Empresas Fechadas de Previdência Complementar (EFPC).

Para fins deste trabalho, o foco de análise concentra-se no primeiro subsistema, mais especificamente no RGPS, que é o principal regime previdenciário do país e abrange o maior contingente de pessoas. Os benefícios emitidos pelo RGPS funcionam como um seguro social para o trabalhador e sua família, por meio da reposição da renda do trabalhador contribuinte quando este perde a capacidade de trabalho, devido à doença, invalidez, idade avançada, morte e desemprego involuntário, ou mesmo em razão de maternidade e reclusão. Os benefícios concedidos pelo RGPS são classificados em três grandes grupos: previdenciários, acidentários e assistenciais. De acordo com o Ministério da Previdência Social (MPS) (2010a), no ano de 2009, a previdência social emitiu 224,8 bilhões de reais em benefícios para 28,1 milhões de pessoas. Esse valor representou 7,15\% do PIB brasileiro.

Com relação às características do RGPS, Afonso e Fernandes (2005) chamam a atenção para o fato de que esse regime, assim como apresentado por Diamond (1977), também funciona como uma política de assistência social para alguns grupos de beneficiários, como no caso da previdência rural e benefícios de prestação continuada (BPC), bem como uma política 
de transferência de renda inter-regional na medida em que o sistema transfere recursos de regiões mais desenvolvidas economicamente para regiões menos desenvolvidas.

Outra característica importante do RGPS é apontada por Ferreira e Souza (2008). Segundo esses autores, os benefícios pagos pela previdência social representam a base de sustentação da economia de um grande número de municípios brasileiros de pequeno porte, com baixa atividade econômica e elevado grau de dependência do setor público. Nesses municípios, a previdência social em conjunto com o setor público constituem os principais responsáveis pela manutenção da atividade econômica local.

Conforme dados do MPS (2009), os valores dos benefícios pagos pela previdência social superam o Fundo de Participação Municipal (FPM), principal fonte de recursos para a maioria dos municípios, em aproximadamente 60\% dos 5.564 municípios brasileiros. Em mais de 3.449 cidades, o total de pagamentos relativos a benefícios previdenciários é superior ao volume de recursos que esses municípios receberam do FPM.

Reconhecendo a previdência social como uma das principais políticas sociais no Brasil, especialmente para os municípios de pequeno porte, diversos estudos têm enfatizado o seu impacto sobre a economia desses municípios. Entre esses estudos, destacam-se os realizados por França (2004), Caetano (2006), Costanzi e Barbosa (2009) e Carvalho (2010).

França (2004) avaliou o impacto da previdência social na economia dos municípios brasileiros por meio de uma análise comparativa do pagamento dos benefícios previdenciários com o Índice Municipal de Desenvolvimento Humano (IDH-M). De acordo com o autor, entre os 100 municípios brasileiros mais bem situados no ranking do IDH-M, 92 apresentaram volume de benefícios superior ao FPM. Entretanto, nos 100 piores, o número de municípios com benefícios previdenciários em volume superior ao FPM foi apenas 28.

Costanzi e Barbosa (2009), similarmente ao trabalho desenvolvido por França (2004), analisaram o saldo da previdência social por meio da comparação entre a arrecadação e o pagamento de benefícios. Carvalho (2010) também comparou o valor dos benefícios previdenciários rurais e urbanos com as fontes de recursos igualmente importantes no orçamento público municipal, adotando, como área de análise, os municípios do estado do Rio Grande do Norte. Os resultados encontrados por Carvalho (2010) e Costanzi e Barbosa (2009) se assemelham àqueles obtidos por França (2004).

Caetano (2006), por sua vez, testou a progressividade regional do RGPS por meio de um modelo estatístico, que permitiu verificar como a previdência social afeta a distribuição de renda do ponto de vista regional, mais especificamente, municipal. A base de dados utilizada no estudo refere-se à arrecadação e despesa previdenciária, ao Produto Interno Bruto (PIB) municipal, à quantidade e proporção de idosos na população, ao PIB per capita e ao valor do benefício previdenciário médio. Como resultado, o autor concluiu que os benefícios da previdência social (RGPS) constituem um potencial instrumento de distribuição de renda das regiões mais ricas para as mais necessitadas, pelo menos no curto prazo.

No cenário internacional, os sistemas de previdência social também constituem uma importante arena das políticas públicas e gastos sociais e têm sido destaque na literatura acadêmica. Entre os principais trabalhos sobre o tema, destacam-se aqueles realizados por Diamond (1977) e Barro e MacDonald (1979). O primeiro examinou as razões para a existência 
de um sistema público de previdência social, destacando a função de redistribuição de renda e a provisão de seguros onde o mercado não é eficiente. O segundo analisou, empiricamente, a relação entre a previdência social e o comportamento de consumo por meio de um painel de dados para uma amostra de 16 países industrializados. Não obstante, os resultados do estudo foram inconclusivos.

Entre os estudos mais recentes sobre o tema, encontram-se aqueles realizados por Bellettini e Ceroni (2000) e Goudswaard e Caminada (2010). Bellettini e Ceroni (2000) analisaram a relação entre as despesas de segurança social e de crescimento econômico referentes a 61 países. Os autores identificaram a existência de uma associação estatisticamente significativa entre as despesas de segurança social e de crescimento. Essa associação é positiva e tende a ser relativamente superior em países pobres. Por sua vez, Goudswaard e Caminada (2010) investigaram o impacto redistributivo do rendimento de sistemas públicos de previdência social versus sistemas privados em países da Organização para Cooperação e Desenvolvimento Econômico (OCDE). Os resultados desse estudo evidenciam uma relação positiva entre os gastos com previdência social e a redistribuição de renda.

A partir da literatura internacional apontada acima, nota-se que os trabalhos empíricos têm concentrado suas investigações na análise de dados agregados para países. Nesse sentido, parecem ser escassos os trabalhos que avaliem os impactos dos gastos com previdência social nos contextos subnacionais. Uma explicação para essa situação pode estar associada a uma possível limitação de dados sobre o tema para os níveis subnacionais.

Diante da importância socioeconômica da previdência social, particularmente para os municípios de pequeno porte, o objetivo principal deste artigo é analisar o impacto da previdência social, mais especificamente dos benefícios emitidos pelo RGPS, sobre a eficiência na promoção do desenvolvimento socioeconômico entre os municípios de pequeno porte do estado de Minas Gerais.

Para tanto, como unidades de análise, foram selecionados 675 municípios mineiros com população inferior a 20 mil habitantes, no ano de 2010. A escolha da amostra pode ser justificada com base em dois argumentos. O primeiro está associado à predominância de municípios de pequeno porte em Minas Gerais, pois, aproximadamente, 80\% dos municípios mineiros têm população inferior a 20 mil habitantes. O segundo argumento fundamenta-se no fato de os benefícios emitidos pela previdência social tenderem a ter uma participação mais elevada nos municípios de menor porte, conforme apresentado por Ferreira e Souza (2008) e Reis, Silveira e Braga (2011).

Ademais, cabe destacar que Minas Gerais apresenta o maior número de municípios entre os estados brasileiros; são 853 municípios que representam 15,3\% dos municípios do país.

Com relação à participação da previdência social no estado de Minas Gerais, ressalta-se que a população do estado foi a segunda maior beneficiária dos recursos emitidos do RGPS no ano de 2010, sendo beneficiada com $11,27 \%$ do volume total de benefícios pagos no país. No mesmo ano, o estado de Minas Gerais foi responsável por 8,89\% de toda a arrecadação previdenciária do país, ocupando a terceira posição entre os estados que mais contribuíram com a arrecadação para o RGPS, ficando atrás apenas dos estados de São Paulo e Rio de Janeiro (MPS, 2010a). 


\section{Desigualdade regional, gastos públicos e previdência social nos municípios de Minas Gerais}

Um dos principais problemas socioeconômicos brasileiros refere-se à desigualdade entre indivíduos e regiões (Furtado, 1967; Rocha, 1998; Maciel, Piza e Penoff, 2009). Segundo Rocha (1998), embora, desde a década de 1950, o governo venha buscando implementar políticas públicas voltadas para a mitigação do problema da desigualdade regional no país, as diferenças entre as regiões permanecem em níveis elevados quaisquer que sejam os critérios utilizados para sua mensuração.

No estado de Minas Gerais, área de abrangência deste estudo, historicamente, a desigualdade regional constitui uma das principais características (Figueiredo e Diniz, 2000; Shikida, Milton e Araujo Junior, 2007). A grande heterogeneidade que caracteriza o estado se apresenta tanto em variáveis econômicas quanto geográficas e sociais, podendo, em parte, ser explicada em razão de sua extensão territorial e concentração da produção e da população em determinadas áreas.

De acordo com os dados do Instituto Brasileiro de Geografia e Estatística (IBGE) (2011), Minas Gerais apresenta uma grande disparidade quanto à distribuição de sua população e ao porte dos seus municípios. Os municípios de pequeno porte (população inferior a 20 mil habitantes) representam aproximadamente $80 \%$ dos municípios do estado; no entanto, a população residente nesses municípios corresponde apenas a $26 \%$ da população total de Minas Gerais. Além disso, nos municípios de pequeno porte mais de um terço da população vive no meio rural e essa população corresponde a cerca de $60 \%$ da população rural total do estado.

A disparidade regional existente em Minas Gerais também pode ser observada, quando outros indicadores são analisados, tais como a taxa de analfabetismo, o rendimento mensal médio domiciliar per capita e a proporção de idosos na população total dos municípios. Segundo dados do IBGE (2011), os municípios de menor porte, isto é, com menos habitantes, tendem a apresentar maiores proporções de adultos analfabetos (taxa de analfabetismo de aproximadamente 14\% nos municípios com menos de 20 mil habitantes contra uma taxa média de 8,3\% para todos os municípios do estado) e menores rendimentos domiciliares per capita (rendimento de cerca de $\mathrm{R} \$ 400,00$ per capita nos municípios de pequeno porte contra um rendimento médio per capita estadual de $\mathrm{R} \$ 641,00)$.

Quanto à proporção de idosos na população total, percebe-se que ela tende a ser maior nos municípios menores (a proporção de idosos na população é de aproximadamente 13\% nos municípios menores contra uma taxa média de idosos na população estadual de 11,8\%). Essa condição pode ser explicada pelo fato de que, quanto menor o porte do município, mais incipiente é a economia local e mais escassas são as oportunidades de trabalho, o que faz com que a população em idade ativa migre para outros municípios e regiões em busca de oportunidades de trabalho.

Por outro lado, a elevada proporção de idosos na população desempenha um importante papel na economia desses pequenos municípios em função do acesso dessa parcela da população aos benefícios da previdência social. Conforme Mendes e Sousa (2006:289), "con- 
trariamente à evidência internacional, a maior proporção de pessoas com mais de 60 anos reduz as despesas públicas locais". Como explicação para essa situação, os autores argumentam que "no Brasil, as pessoas mais velhas estão relativamente em melhor situação quando comparadas com jovens e, por essa razão, podem consumir bens privados, substitutos dos serviços públicos".

Diante desse cenário de desigualdade e vulnerabilidade socioeconômica, que afeta a população dos municípios de menor porte, torna-se cada vez mais relevante o papel desempenhado pelo poder público (União, estados e municípios) como indutor do desenvolvimento regional, por meio da descentralização dos recursos públicos e de políticas públicas sociais - caso da distribuição de recursos por meio das transferências governamentais visando à equidade social e da previdência social que é objeto deste estudo.

Com relação às transferências governamentais, em 2009, segundo dados do Finbra (2010), cerca de 75\% da receita pública per capita dos municípios do estado de Minas Gerais provinham das transferências da União e do estado e 25\%, das receitas tributárias próprias. Para os municípios com menos de 5 mil habitantes as transferências correspondiam a 93,4\% do total das receitas municipais. Para os municípios com população de 5.001 a 10 mil habitantes e de 10.001 a 20 mil, as receitas de transferências governamentais correspondiam, respectivamente, a $90,2 \%$ e $88,7 \%$ da receita total. Nesse sentido, assim como apresentado por Magalhães (2007), quanto menor o porte dos municípios, maiores são as parcelas dos recursos provenientes das transferências governamentais, o que indica uma dependência financeira dos municípios de pequeno porte em relação a essas transferências.

Entre as principais transferências governamentais destinadas aos municípios no Brasil, destaca-se a participação dos recursos provenientes da cota-parte do FPM e da cota-parte do Imposto sobre Circulação de Mercadorias e Prestação de Serviços (ICMS), que representaram, em 2009 , aproximadamente $31 \%$ e $27 \%$ do total de recursos transferidos pela União e pelo estado, respectivamente.

Quanto ao papel das políticas sociais, mais precisamente, da previdência social na economia dos municípios de Minas Gerais, destaca-se que, no ano de 2009, os valores dos benefícios pagos pela previdência social foram superiores aos repasses de FPM em 498 municípios, ou seja, em aproximadamente 58\% dos municípios do estado. Destes 498 municípios, 64,2\% possuem menos de 20 mil habitantes, ou seja, são municípios de pequeno porte.

Outro indicador interessante para análise da participação da previdência social na economia dos municípios refere-se ao saldo de arrecadação da previdência social, que é a diferença entre o volume arrecadado e o volume de benefícios pagos pela previdência social em determinado município. Esse indicador permite analisar o papel desempenhado pela previdência social como um mecanismo de transferência de renda do ponto de vista regional. Isso ocorre pelo fato de que, nos municípios maiores e com atividade econômica mais desenvolvida, o volume de arrecadação tende a ser superior ao de benefícios pagos.

Segundo dados do MPS (2010b), em 2009, apenas nos municípios de grande porte, com população superior a 500 mil habitantes, o volume de arrecadação foi superior ao volume de benefícios recebidos. Isso denota a presença de transferências de renda inter-regionais, dado 
que parte do valor arrecadado nos grandes municípios está sendo destinada para o pagamento de benefícios nos municípios de menor porte. Esses resultados são corroborados por Afonso e Fernandes (2005), que apontaram o funcionamento das aposentadorias e pensões como um mecanismo de transferência de renda das regiões mais ricas para as mais pobres.

A partir dos dados apresentados nesta seção e, ainda, de acordo com MPS (2009), pode-se inferir que o volume de recursos da previdência social mensalmente injetado na economia dos municípios de Minas Gerais é, para muitos deles, a garantia da movimentação da atividade econômica, em especial os setores de comércio e de serviços.

\section{Metodologia}

O desenvolvimento empírico deste artigo ocorreu em duas etapas de investigação, que serão explicitadas nesta seção metodológica. Na primeira etapa concentrou-se na análise da eficiência municipal na promoção do desenvolvimento socioeconômico, por meio da geração dos escores de eficiência dos municípios mineiros de pequeno porte, enquanto na segunda buscou avaliar os impactos da previdência social sobre os escores de eficiência municipal, obtidos na primeira etapa. Esta segunda etapa foi realizada controlando-se por outros fatores determinantes da eficiência municipal.

\subsection{Análise envoltória de dados}

Para a realização da primeira etapa da investigação, utilizou-se a análise envoltória de dados (DEA) que é uma técnica frequentemente empregada para a análise de eficiência no setor público (Gupta e Verhoeven, 2001; Afonso, Schuknecht e Tanzi, 2006). A técnica de análise envoltória de dados é baseada em programação linear e usada para calcular a eficiência relativa de um grupo de unidades de produção (Decision Making Units — DMUs), por meio da utilização de medidas de insumos e produtos.

A programação linear, da qual se utiliza a DEA, é um processo que consiste em maximizar ou minimizar uma função objetivo, levando em consideração equações condicionantes ou restrições. Portanto, trata-se de um problema de máximo (orientação produto) ou mínimo (orientação insumo) sujeito a restrições.

De forma geral, no primeiro caso, as DMUs são comparadas em relação a seus insumos. O parâmetro de eficiência estimado sugere o percentual de redução possível no nível de insumos utilizados, dado o nível de produto. No segundo caso, as DMUs são comparadas em relação a seus produtos, isto é, o modelo DEA com orientação-produto procura maximizar o aumento proporcional nos níveis de produto, mantendo fixa a quantidade de insumos.

Como os municípios, que são as DMUs em questão, sofrem restrições financeiras, e considerando o papel desempenhado pelo setor público como indutor do desenvolvimento socioeconômico, é justificável falar em uma fronteira de produção de bem-estar ou desenvolvimento 
socioeconômico com orientação para o produto. A orientação produto tem sido utilizada por diversos autores, entre os quais destacam-se Shikida, Milton e Araujo Junior (2007), Ribeiro (2008) e Maciel, Piza e Penoff (2009).

Outra variação na técnica de análise envoltória de dados refere-se à hipótese sobre os retornos de escala, que podem ser constantes (CCR) ou variáveis (BCC). De acordo com Ribeiro (2008), a prática mais comum é supor que eles sejam variáveis, hipótese admitida como a menos restritiva. Além disso, de acordo com Maciel, Piza e Penoff (2009), a pressuposição de retornos constantes de escala constitui uma das limitações da técnica original de análise envoltória de dados. A pressuposição de retornos constantes de escala implica que todas as DMUs permaneçam em uma escala ótima de operação. Notadamente, este pressuposto é incompatível com uma série de atividades econômicas e organizações, entre as quais podem ser considerados os municípios, enquanto agentes produtores/prestadores de bens e serviços públicos.

Feitas essas considerações quanto à orientação e aos retornos de escalas da DEA, para os fins desse trabalho optou-se pela técnica com orientação produto e retornos variáveis de escalas (BCC).

\subsubsection{DEA 2 estágios - análise dos fatores determinantes}

Segundo Ribeiro (2008), uma limitação da técnica de análise envoltória de dados consiste em considerar apenas insumos de natureza discricionária, ou seja, aqueles que podem ser controlados ou alterados pelas unidades de decisão. Dessa forma, o uso da DEA, no presente estudo, desconsideraria os efeitos dos fatores que estão fora do controle da gestão pública, mas que afetam a eficiência municipal ao menos a curto e médio prazos. Isso significa que a DEA não permite identificar os principais determinantes municipais que contribuem para os resultados de eficiência.

Na literatura brasileira, ainda são poucos os trabalhos sobre eficiência que têm se preocupado em avaliar o impacto dos fatores exógenos ou variáveis ambientais sobre a eficiência no setor público. Alguns dos precursores na análise dos fatores determinantes da eficiência do setor público no Brasil foram Delgado e Machado (2007) e Ribeiro (2008).

Nesse sentido, a contribuição do presente artigo consiste na investigação dos fatores determinantes da eficiência municipal na promoção do desenvolvimento socioeconômico, com destaque para a análise dos impactos dos benefícios pagos pela previdência social, foco deste trabalho. Para identificar os fatores determinantes da eficiência municipal, foi utilizado o modelo estatístico de regressão Tobit aplicado a um painel de dados referentes aos municípios mineiros de pequeno porte, no período de 2000 e 2005 a 2009.

A variável dependente do modelo de regressão foi o índice de eficiência estimado com orientação produto e retornos variáveis de escalas (BCC), por meio da DEA. As variáveis independentes, conforme descrição apresentada na próxima seção, consideraram quatro grupos de dados: a) características econômico-financeiras, tais como PIB municipal, participação do PIB 
agropecuária no PIB municipal, nível de desenvolvimento tributário e econômico do município; b) características demográficas: população, proporção da população em área urbana, proporção da população inativa; c) características sociais dos municípios: renda familiar e nível educacional; e d) variável de interesse que busca identificar o impacto da previdência social sobre a eficiência municipal na geração de bem-estar social.

O modelo de regressão Tobit tem sido utilizado com frequência para a estimação dos efeitos das variáveis ambientais sobre os escores de eficiência obtidos por meio da DEA, devido ao fato de os escores de eficiência serem restritos ao intervalo [0,1]. Em função dessa restrição, as estimativas por mínimos quadrados ordinários (MQO) podem ser inconsistentes. Em linhas gerais, o caso base da regressão Tobit é similar à regressão por MQO, mas assume uma distribuição normal truncada no lugar da distribuição normal e emprega métodos de estimação de máxima verossimilhança (Greene, 2003).

Os modelos de dados em painel permitem o exame de efeitos fixos ou aleatórios de uma determinada observação ou dos períodos de tempo nos escores de eficiência. No caso dos modelos de efeitos aleatórios, de acordo com Greene (2003), os mais frequentemente utilizados, as premissas básicas são: o efeito aleatório $u_{i}$ é o mesmo para todos os períodos e este não deve ser correlacionado com os demais regressores; os coeficientes angulares são os mesmos para todos os grupos e períodos; e $\varepsilon_{i t}$, o componente estocástico do modelo, não é correlacionado entre períodos. A forma funcional do modelo de efeitos aleatórios é dada por:

$$
y_{i t}=X_{i t} \beta+\mathrm{u}_{i}+\varepsilon_{i t}
$$

em que: $i$ denota a observação; $t$ denota o período de tempo; $y_{i t}$ denota a variável dependente; e $X_{i t}$ denota o vetor de variáveis independentes.

Como as estimativas do modelo Tobit por máxima verossimilhança não produzem resultados imediatos, dada a condição de não negatividade da variável dependente, torna-se necessário calcular os efeitos marginais, cuja derivação pode ser observada em Wooldridge (2002). Conhecidos os efeitos marginais das variáveis incluídas no modelo, é possível determinar o impacto de cada uma delas sobre o índice de eficiência, indicando, assim, os fatores determinantes da eficiência dos municípios investigados, bem como o impacto da previdência social sobre essa eficiência.

\subsection{Fonte dos dados e variáveis selecionadas}

Neste estudo, estão combinadas quatro fontes de dados. O banco de dados do Índice Mineiro de Responsabilidade Social (IMRS) (Fundação João Pinheiro, 2011) possibilitou a coleta de variáveis tanto de insumos quanto dos fatores ambientais determinantes da eficiência municipal (econômico-financeiro e demográfico). Das bases de dados do Índice Firjan de Desenvolvimento Municipal (IFDM) (Federação das Indústrias do Estado do Rio de Janeiro, 2011) foram coletados os indicadores de produto. A base de dados com as Estatísticas Municipais 
da Previdência Social (EMPS) (MPS, 2010b) e o Censo Demográfico (IBGE, 2011) possibilitaram o levantamento da variável de interesse, ou seja, relacionada à previdência social, e das variáveis ambientais que representam as condições sociais dos municípios pesquisados, respectivamente.

Nesse sentido, as bases do IMRS/FJP-MG e IFDM/Firjan permitiram tratar os aspectos relacionados à eficiência municipal, enquanto as bases de EMPS/MPS, IBGE e novamente do IMRS/FJP-MG permitiram a abordagem dos determinantes do resultado da gestão municipal na promoção do desenvolvimento socioeconômico.

Foi considerado o período de análise 2000 e 2005 a 2009. Os anos anteriores a 2000, os anos de 2001 a 2004 e os anos posteriores a 2009 não foram considerados, em função da indisponibilidade dos dados necessários.

\subsubsection{Insumos e produtos (DEA)}

A partir da base de dados do IMRS, foram coletadas as variáveis de gastos anuais per capita por atividade de cada município mineiro que compõe a amostra. Os gastos por atividade foram computados no indicador gastos municipais per capita (ano), que foi utilizado como indicador de insumo para a estimação do modelo de eficiência municipal. Cabe enfatizar que o indicador gastos municipais per capita representa o somatório dos gastos, no ano, com as atividades de saúde, educação, infraestrutura, agropecuária, reforma agrária e colonização, desenvolvimento econômico, apoio ao trabalho, segurança pública, habitação, saneamento, meio ambiente, preservação do patrimônio cultural, difusão cultural, esporte e lazer, assistência social e cidadania e outras atividades, dividido pela população do município no ano.

Os indicadores de produto utilizados, isto é, de desenvolvimento socioeconômico, correspondem às três dimensões do IFDM (emprego e renda, saúde e educação). Estes indicadores consistem em uma medida de bem-estar, que agrega diversos indicadores sociais com o objetivo de definir uma medida de grau do desenvolvimento municipal. Tal como o Índice de Desenvolvimento Humano (IDH) do Programa das Nações Unidas para o Desenvolvimento (Pnud), o IFDM varia entre 0 e 1: quanto mais próximo da unidade, maior o grau de desenvolvimento social do município. O IFDM/Firjan está disponível apenas para os anos de 2000 e 2005 a 2009.

\subsubsection{Determinantes da eficiência municipal na promoção do desenvolvimento socioeconômico}

De acordo com Rayp e Van de Sijp (2007), a eficiência no setor público é determinada, principalmente, pelas variáveis estruturais ou econômico-financeiras. Segundo os autores, a eficiência municipal seria, positivamente, afetada pela base econômica, na medida em que a mesma define o volume de riqueza a ser taxada e, portanto, a base fiscal do nível de governo 
em questão. Neste artigo, para verificar os impactos dos fatores econômico-financeiros sobre o desempenho municipal, foram utilizados os seguintes indicadores: (i) PIB municipal per capita (quanto maior o PIB municipal, maior tende a ser a base econômica municipal e maior a sua capacidade de arrecadação); (ii) participação do PIB agropecuária no PIB municipal total (razão entre o PIB agropecuária e o PIB total; quanto maior a participação do PIB agropecuária, menos desenvolvida tende a ser a base econômica do município e menor sua capacidade de arrecadação própria); e (iii) Índice de Desenvolvimento Tributário e Econômico (IDTE) (indicador que varia de 0 a 1 e mensura a capacidade do município para financiar os serviços que oferta e presta à sociedade com as receitas que possui).

Quanto maior o IDTE, maior o grau de desenvolvimento da economia do município e, consequentemente, maior a capacidade da administração pública de financiamento de suas atividades com receitas geradas por sua base econômica, isto é, menor sua dependência de transferências de outros níveis de governo para a cobertura e financiamento de seus gastos.

Além dos indicadores econômicos financeiros, outros fatores que podem afetar a eficiência municipal estão, diretamente, associados ao nível e à natureza das demandas por bens e serviços apresentadas pela população. Dessa forma, a análise dos fatores demográficos tornase uma variável importante a ser considerada, pois, quanto maior a população, maior o desafio para as políticas públicas, e quanto maior o grau de urbanização nos pequenos municípios, maior a facilidade na prestação dos serviços públicos (Lubambo, 2006). Ademais, conforme apresentado por Rayp e Van de Sijp (2007), quanto menor a população, maior a proximidade com a administração pública e maior a governança.

Para avaliar os impactos dos fatores demográficos sobre a eficiência municipal, foram utilizadas as seguintes variáveis: (i) população (número de habitantes); (ii) taxa de urbanização (razão entre população urbana e população total); e (iii) razão de dependência demográfica (razão entre a população jovem, 0 a 14 anos, mais a idosa, acima de 65 anos, e a população em idade ativa, 15 a 64 anos).

Entre outros fatores importantes para a determinação dos níveis de eficiência municipal na promoção do desenvolvimento socioeconômico, destacam-se as condições sociais, tais como a escolaridade e o nível de renda familiar. Para analisar os impactos dos fatores sociais sobre a eficiência municipal, foram utilizados os seguintes indicadores: (i) taxa de analfabetismo da população com 15 anos ou mais; e (ii) renda familiar per capita anual.

Deve-se ressaltar que as variáveis taxa de analfabetismo e renda familiar per capita são informações provenientes dos censos demográficos realizados, decenalmente, pelo IBGE e, por isso, essas informações foram coletadas para os anos 2000 e 2010. Nesse sentido, os valores para o período 2004 a 2009 foram obtidos por meio do cálculo de uma taxa média geométrica de crescimento anual (TMCA) entre os anos 2000 e 2010. Por se tratar de variáveis que não apresentam grandes variações em curtos períodos de tempo, acredita-se que o uso da TMCA seja uma opção aceitável.

Além dos fatores acima mencionados, outro que pode impactar significativamente a eficiência municipal na promoção do desenvolvimento socioeconômico e que consiste no objeto de análise do presente estudo refere-se aos pagamentos de benefícios da previdência social. 
Isso porque o volume de benefícios oriundos da previdência social, em geral, supera a principal fonte de arrecadação da grande maioria dos municípios brasileiros, o FPM. De forma complementar, conforme apresentado por Ferreira e Souza (2008), os benefícios da previdência social representam a base de sustentação da economia de um grande número de municípios de baixa renda, que, em geral, são municípios de menor porte.

Para investigar os impactos da previdência social sobre a eficiência na promoção do desenvolvimento socioeconômico entre os municípios de pequeno porte do estado de Minas Gerais, utilizou-se a variável valor per capita anual dos benefícios da previdência social recebidos nos municípios.

No quadro 1 apresenta-se um resumo de todas as variáveis discutidas nessa seção, bem como a relação esperada dessas variáveis com a variável dependente (escore de eficiência municipal) do modelo de regressão estimado.

Quadro 1

Descrição das variáveis ambientais utilizadas no modelo

\begin{tabular}{|clc|}
\hline \multirow{2}{*}{ Dimensão } & \multicolumn{1}{c}{ Variáveis Ambientais } & $\begin{array}{c}\text { Impacto } \\
\text { Esperado }\end{array}$ \\
\hline \multirow{2}{*}{$\begin{array}{c}\text { Econômico- } \\
\text {-financeira }\end{array}$} & PIB municipal per capita (R\$/ano) & + \\
& Índice de Desenvolvimento Tributário e Econômico (0 a 1) & - \\
& População (número de habitantes) & + \\
Demográfica & Taxa de urbanização (\%) & - \\
& Razão de dependência demográfica (\%) & - \\
Social & Escolaridade (Taxa de analfabetismo (\%) - pessoas com 15 anos ou mais) & + \\
Previdência & Renda familiar per capita (R\$/ano) & + \\
\hline
\end{tabular}

Fonte: Elaborado pelos autores.

\section{Resultados e discussão}

Os resultados foram analisados em duas seções. Na seção 4.1 apresenta-se a análise da eficiência entre os municípios pesquisados. Na seção 4.2 são investigados os fatores determinantes da eficiência municipal.

\subsection{Eficiência na promoção do desenvolvimento socioeconômico entre os municípios investigados}

Na tabela 1 apresenta-se a análise exploratória das variáveis empregadas na mensuração da eficiência relativa dos 675 municípios mineiros de pequeno porte que compõem a amostra. 
Tabela 1

Análise exploratória das variáveis empregadas na mensuração da eficiência entre os municípios mineiros de pequeno porte (2000 e 2005 a 2009)

\begin{tabular}{|c|c|c|c|c|c|}
\hline Índice & Ano & Máximo & Mínimo & Média & Desvio Padrão \\
\hline \multirow{6}{*}{ Gasto per capita (Input) } & 2000 & $7.392,10$ & 506,01 & $1.348,35$ & 705,14 \\
\hline & 2005 & $6.706,07$ & 581,08 & $1.301,02$ & 651,93 \\
\hline & 2006 & $7.645,72$ & 663,51 & $1.568,69$ & 786,21 \\
\hline & 2007 & 7.109,39 & 681,16 & $1.617,74$ & 767,91 \\
\hline & 2008 & $7.804,38$ & 763,71 & $1.792,57$ & 831,70 \\
\hline & 2009 & $8.263,46$ & 797,25 & $1.840,12$ & 899,11 \\
\hline \multirow{6}{*}{ Emprego \& Renda (Output 1) } & 2000 & 0,730 & 0,044 & 0,318 & 0,112 \\
\hline & 2005 & 0,744 & 0,034 & 0,360 & 0,104 \\
\hline & 2006 & 0,762 & 0,113 & 0,360 & 0,091 \\
\hline & 2007 & 0,712 & 0,068 & 0,346 & 0,090 \\
\hline & 2008 & 0,978 & 0,000 & 0,349 & 0,128 \\
\hline & 2009 & 0,843 & 0,097 & 0,347 & 0,094 \\
\hline \multirow{6}{*}{ Educação (Output 2) } & 2000 & 0,844 & 0,383 & 0,611 & 0,100 \\
\hline & 2005 & 0,854 & 0,414 & 0,652 & 0,078 \\
\hline & 2006 & 0,888 & 0,412 & 0,675 & 0,069 \\
\hline & 2007 & 0,907 & 0,511 & 0,723 & 0,060 \\
\hline & 2008 & 0,944 & 0,431 & 0,703 & 0,082 \\
\hline & 2009 & 0,912 & 0,513 & 0,754 & 0,063 \\
\hline \multirow{6}{*}{ Saúde (Output 3) } & 2000 & 0,969 & 0,186 & 0,641 & 0,132 \\
\hline & 2005 & 0,946 & 0,411 & 0,728 & 0,108 \\
\hline & 2006 & 0,955 & 0,361 & 0,737 & 0,110 \\
\hline & 2007 & 0,955 & 0,364 & 0,753 & 0,105 \\
\hline & 2008 & 0,977 & 0,392 & 0,767 & 0,101 \\
\hline & 2009 & 0,980 & 0,501 & 0,781 & 0,093 \\
\hline
\end{tabular}

Fonte: Firjan (2010), Fundação João Pinheiro (2011).

Nota: entre os 675 municípios da amostra, sete não possuíam informações disponíveis sobre gastos públicos para o ano de 2000. Assim, os valores dos gastos per capita desses municípios no ano de 2000 foram considerados iguais aos gastos apresentados por eles em 2001.

Na tabela 2 apresenta-se a distribuição de frequência dos escores de eficiência dos municípios mineiros de pequeno porte, gerados pela DEA, com orientação para o produto e retornos variáveis à escala para cada um dos anos analisados. Com objetivo de obter maior robustez nas estimativas, utilizou-se o bootstrap (reamostragem) aos estimadores de eficiência obtidos com a DEA como parte dos procedimentos analíticos. O método consiste em aplicar o bootstrap para aproximar, assintoticamente, a distribuição dos estimadores de eficiência, conforme sugerido por Marques e Silva (2006) e Fonseca e Ferreira (2009). 
Tabela 2

Distribuição dos municípios mineiros de pequeno porte, por nível de eficiência (2000 e 2005 a 2009)

\begin{tabular}{|lcccccc|}
\hline & \multicolumn{5}{c|}{ Intervalo de Eficiência } \\
\cline { 2 - 7 } & Ano & $0 \%-20 \%$ & $20 \%-40 \%$ & $40 \%-60 \%$ & $60 \%-80 \%$ & $80 \%-100 \%$ \\
\hline \multirow{3}{*}{ Número de } & 2000 & 0 & 0 & 43 & 317 & 315 \\
Ocorrência & 2005 & 0 & 0 & 4 & 241 & 430 \\
& 2006 & 0 & 0 & 4 & 182 & 489 \\
& 2007 & 0 & 0 & 0 & 113 & 562 \\
& 2008 & 0 & 0 & 6 & 240 & 429 \\
Frequência Relativa & 2009 & 0 & 0 & 0 & 112 & 563 \\
(\%) & 2000 & - & - & $6,4 \%$ & $47,0 \%$ & $46,7 \%$ \\
& 2005 & - & - & $0,6 \%$ & $35,7 \%$ & $63,7 \%$ \\
& 2006 & - & - & $0,6 \%$ & $27,0 \%$ & $72,4 \%$ \\
& 2007 & - & - & - & $16,7 \%$ & $83,3 \%$ \\
& 2008 & - & - & $0,9 \%$ & $35,6 \%$ & $63,6 \%$ \\
Frequência Absoluta & 2009 & - & - & - & $16,6 \%$ & $83,4 \%$ \\
\hline (\%) & 2000 & - & - & $6,4 \%$ & $53,3 \%$ & $100,0 \%$ \\
& 2005 & - & - & $0,6 \%$ & $36,3 \%$ & $100,0 \%$ \\
& 2006 & - & - & $0,6 \%$ & $27,6 \%$ & $100,0 \%$ \\
& 2007 & - & - & - & $16,7 \%$ & $100,0 \%$ \\
& 2008 & - & - & $0,9 \%$ & $36,4 \%$ & $100,0 \%$ \\
\hline
\end{tabular}

Fonte: Resultados da pesquisa.

A partir dos resultados apresentados na tabela 2 nota-se que a maioria dos municípios investigados apresentou escores de eficiência com valores concentrados nos intervalos superiores, próximos das fronteiras de eficiência estimadas para cada ano. Esses resultados representam uma característica dos modelos BCC que, diferentemente dos modelos CCR, retornam escores de eficiência maiores. Em outras palavras, os modelos com retornos variáveis de escala identificam mais DMUs eficientes do que os modelos com retorno constante de escala.

Com o objetivo de realizar uma análise da distribuição geográfica dos resultados alcançados com o modelo utilizado para o cálculo da eficiência, na tabela 3 é apresentado o quadro geral do estado de Minas Gerais, analisado por agrupamento de regiões de planejamento. Cada agrupamento foi formado por duas regiões de planejamento e cada agrupamento foi realizado com base na proximidade geográfica das regiões, bem como na similaridade dos indicadores econômicos e sociais das mesmas. 
Tabela 3

Análise exploratória dos escores de eficiência por agrupamentos de regiões de planejamento do estado de Minas Gerais

\begin{tabular}{|lcccccc|}
\hline Regiões & Observações & Proporção & Média & $\begin{array}{c}\text { Desvio } \\
\text { Padrão }\end{array}$ & Mínimo & Máximo \\
\hline Total & 4.050 & $100,00 \%$ & 0,835 & 0,090 & 0,472 & 0,993 \\
Sul e Triângulo & 894 & $22,07 \%$ & 0,888 & 0,066 & 0,595 & 0,992 \\
Noroeste e Alto Paranaíba & 222 & $5,48 \%$ & 0,875 & 0,075 & 0,531 & 0,992 \\
Central e Centro-Oeste de Minas & 924 & $22,81 \%$ & 0,849 & 0,075 & 0,576 & 0,989 \\
Rio Doce e Zona da Mata & 1.284 & $31,70 \%$ & 0,825 & 0,084 & 0,512 & 0,993 \\
Norte e Jequitinhonha e Mucuri & 726 & $17,93 \%$ & 0,755 & 0,089 & 0,472 & 0,984 \\
\hline
\end{tabular}

Fonte: Resultados da pesquisa.

Os resultados, apresentados na tabela 3, demonstram que o escore médio de eficiência entre os municípios de pequeno porte em Minas Gerais no período analisado (2000 e 2005 a 2009) foi de 0,835. O desvio padrão foi 0,090 e os valores variaram de 0,472 até 0,993. Esse resultado demonstra um elevado grau de homogeneidade nos escores de eficiência dos municípios investigados. Entretanto, deve-se ressaltar que o escore de eficiência, obtido pela técnica de análise envoltória de dados, é uma medida de eficiência relativa, podendo ser considerada apenas para o conjunto de municípios investigados.

Com relação aos escores de eficiência apresentados pelos agrupamentos de regiões de planejamento, observa-se que, de todas as regiões, o agrupamento com as regiões Norte e Jequitinhonha e Mucuri, que são as regiões mais pobres do estado, foi o que apresentou os municípios com os piores escores de eficiência. Por outro lado, os municípios do agrupamento formado pelas regiões Sul e Triângulo, que estão entre as mais desenvolvidas, apresentaram os melhores escores de eficiência no período investigado. Nesse sentido, pode-se inferir que, para a amostra investigada, os municípios de regiões mais pobres tendem a ter o nível médio de eficiência menor do que aqueles de regiões mais favorecidas. Essa constatação é semelhante à realizada por Lopes e Toyoshima (2008) na análise da eficiência dos municípios de Minas Gerais, na gestão dos gastos com saúde e educação.

\subsection{Previdência social e demais determinantes da eficiência municipal}

Para avaliar os fatores determinantes da eficiência municipal na promoção do desenvolvimento socioeconômico, procedeu-se à estimação do modelo de regressão Tobit com dados em painel e efeitos aleatórios. Utilizou-se, como variável dependente, o escore de eficiência gerado através da análise envoltória de dados (primeiro estágio). Na especificação do modelo empírico, considerou-se um conjunto de nove variáveis exógenas agrupadas em quatro dimensões. $\mathrm{Na}$ tabela 4 são apresentadas as estatísticas descritivas dos fatores associados à eficiência 
municipal. No entanto, é importante destacar que algumas variáveis, tais como a participação do PIB agropecuária no PIB municipal e valor dos benefícios emitidos pela previdência social, apresentaram valores iguais a zero ou vazios para alguns municípios em alguns anos investigados. Isso ocorre em função da indisponibilidade de informações ou até mesmo de erros de coleta e tratamento dos dados por parte do órgão ou instituição responsável pela construção dos bancos de dados. Nesse sentido, os valores das variáveis que possuíam informação igual a zero ou vazio foram substituídos pelos valores do próximo ano disponível.

Diferentemente dos resultados identificados a partir da DEA, a análise exploratória das variáveis que compõem a dimensão econômico-financeira mostra uma grande disparidade entre os municípios analisados, pois, mesmo sendo de pequeno porte, os municípios apresentaram características econômico-financeiras bastante heterogêneas, com destaque para a variável PIB per capita, que apresentou uma grande variabilidade no período investigado. Este resultado corrobora o estudo realizado por Figueiredo e Diniz (2000).

Com referência às demais variáveis que compõem a dimensão econômico-financeira, percebe-se que a desigualdade entre os municípios, embora alta, é bem inferior àquela observada na comparação do PIB per capita.

Com relação às variáveis que compõem a dimensão demográfica, nota-se que, em média, os municípios possuem uma população de 7,5 mil habitantes, com cerca de $40 \%$ de sua população residindo no meio rural e com uma razão de dependência demográfica aproximada de 42\%. Ainda nessa dimensão, é importante ressaltar que o critério adotado para a seleção dos municípios, que compõem a amostra, foi o tamanho da população no ano de 2010, que deveria ser inferior a 20 mil habitantes. Nesse sentido, como o ano-base foi 2010, alguns municípios apresentaram população acima de 20 mil habitantes nos anos pesquisados (2000 e 2005 a 2009).

Na dimensão social, os resultados das estatísticas descritivas apontam que ainda é elevada a taxa de analfabetismo entre as pessoas com 15 anos ou mais nos municípios de pequeno porte do estado de Minas Gerais. Os municípios apresentaram uma taxa média de analfabetismo de 17\%, no período de 2000 a 2009, com destaque negativo para a presença de municípios com taxa de analfabetismo superior a 40\%. De forma similar, os resultados para a variável renda média familiar per capita mostraram a existência de município com renda familiar per capita anual média abaixo da linha de pobreza, definida pelo Ministério de Desenvolvimento Social (MDS), que é de $\mathrm{R} \$ 2.784,00 /$ ano ( $\mathrm{R} \$ 232,00 / \mathrm{mês}$ ).

Para a variável relacionada à previdência social, os resultados indicam que o volume anual per capita de benefícios pagos pela previdência corresponde, aproximadamente, a $10,45 \%$ do valor da renda familiar per capita dos municípios que compõem a amostra. Vale ressaltar que, em alguns municípios, esses recursos correspondem a mais de $30 \%$ da renda familiar per capita. Estes resultados são corroborados pelos estudos de Delgado e Cardoso Junior (2000), França (2004) e MPS (2009).

Após a análise exploratória dos fatores determinantes do desempenho municipal, a próxima etapa consistiu em estimar os efeitos desses fatores sobre os escores de eficiência obtidos por meio da análise envoltória de dados (primeiro estágio). O modelo utilizado foi o de regressão Tobit em dados em painel e efeitos aleatórios. Na tabela 5 são apresentados os resultados da regressão Tobit. 


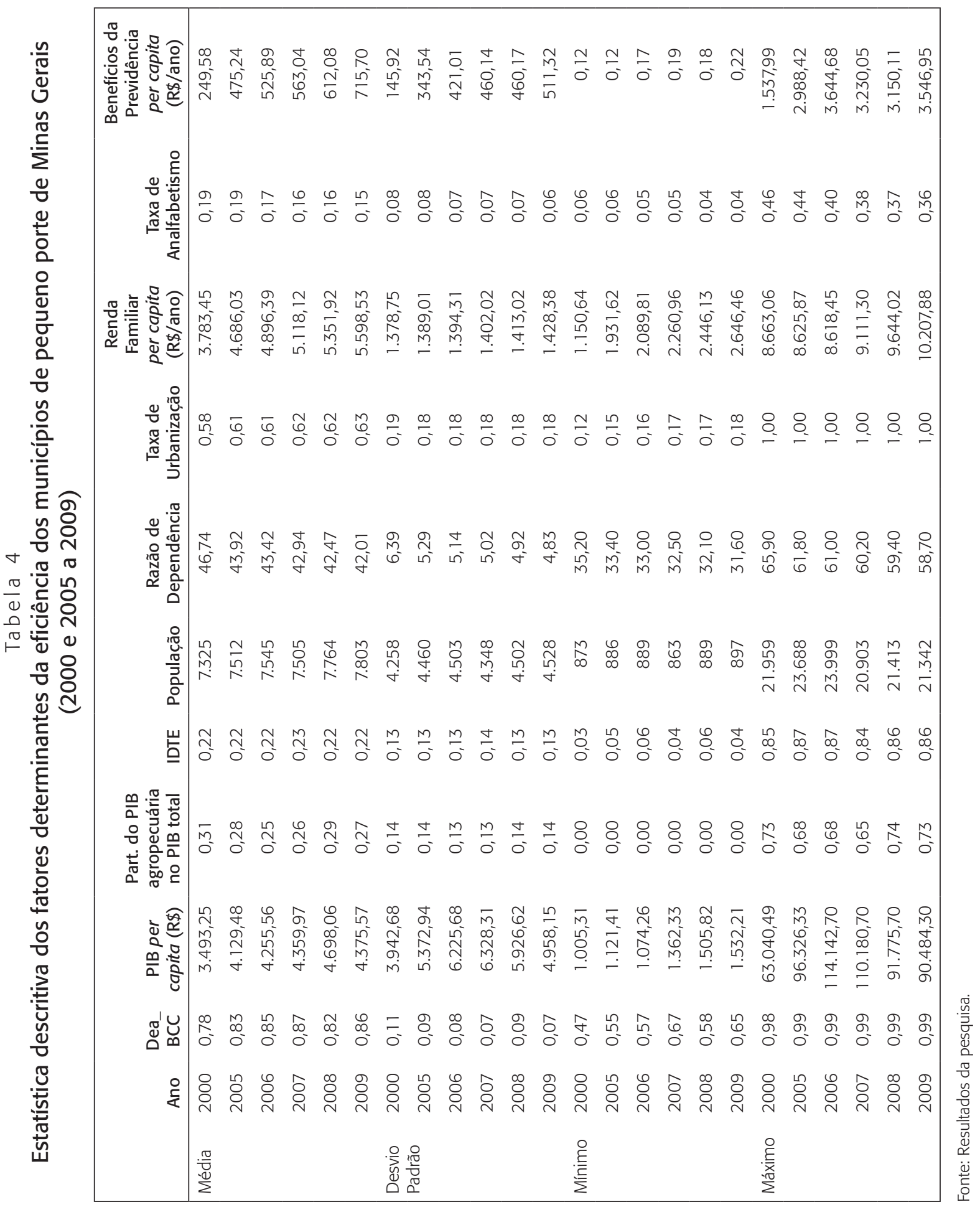

Rev. Adm. Pública - Rio de Janeiro 47(3):623-646, maio/jun. 2013 
Analisando os resultados do modelo de regressão Tobit estimado, verifica-se que este pode ser considerado globalmente válido, pois o $\chi^{2}$ calculado no teste da Razão de Verossimilhança foi significativo a $1 \%\left(\chi^{2}\right.$ crítico $\left.=4.466,65\right)$, indicando, portanto, que as variáveis consideradas explicam os níveis de eficiência dos municípios investigados.

Tabela 5

Previdência social e demais fatores determinantes da eficiência municipal na promoção do desenvolvimento socioeconômico (2000 e 2005 a 2009)

\begin{tabular}{|lccc|}
\hline & Coeficiente & Erro Padrão & Efeito Marginal \\
\hline Constante & $0,2169^{* * *}$ & 0,7925 & - \\
Ln_PIB per capita (R\$ ano) & $-0,0092^{* *}$ & 0,0041 & $-0,0092$ \\
Participação do PIB agropecuária no PIB total (R\$ ano) & $-0,0653^{* * *}$ & 0,0083 & $-0,0653$ \\
Indicador de Desenvolvimento Tributário Econômico (\%) & $-0,0038$ & 0,0136 & $-0,0038$ \\
Ln_População (Número de habitantes) & 0,0018 & 0,0026 & 0,0018 \\
Razão de dependência demográfica (\%) & $-0,0039^{* * *}$ & 0,0005 & $-0,0039$ \\
Taxa de urbanização (\%) & 0,0075 & 0,0063 & 0,0075 \\
Ln_Renda familiar per capita (R\$ ano) & $0,1053^{* * *}$ & 0,0094 & 0,1053 \\
Taxa de analfabetismos (\%) & $-0,2213^{* * *}$ & 0,0328 & $-0,2213$ \\
Ln_Valor dos benefícios da previdência per capita (R\$ ano) & $0,0021^{* *}$ & 0,0010 & 0,0021 \\
\hline
\end{tabular}

Fonte: Resultados da pesquisa.

Nota: os erros padrão foram estimados por bootstrap, $e^{* *}, * * *$ correspondem significância a 10\%, 5\% e 1\%, respectivamente.

Consistente com o fato de os benefícios da previdência social, nos pequenos municípios, constituírem uma importante fonte de renda, o coeficiente positivo, atrelado à variável valor dos benefícios emitidos pela previdência social, apresentou significância estatística ao nível de 1\%. Nesse sentido, esse resultado pode ser considerado mais uma evidência da importância socioeconômica da previdência social no Brasil, especialmente nos municípios com menor porte.

Com relação aos demais determinantes da eficiência municipal na promoção do desenvolvimento socioeconômico, constatou-se que, na dimensão estrutural ou econômicofinanceira, apenas as variáveis PIB per capita e a participação do PIB agropecuária no PIB municipal total apresentaram impactos significativos sobre a eficiência dos municípios investigados.

O impacto negativo da variável participação do PIB agropecuária no PIB municipal total está de acordo com a expectativa teórica, dado que a participação do setor agropecuário na economia municipal indica a presença de uma economia com baixa agregação de valor e menor capacidade de arrecadação. Por outro lado, o impacto negativo do PIB municipal per capita sobre a eficiência municipal contrariou a expectativa inicial. Teoricamente, esperava-se encontrar um impacto positivo do PIB sobre a eficiência municipal, pois, quanto maior a produção econômica do município, maior seria a capacidade de arrecadação e, consequentemente, maior a capacidade de prestação de serviços por parte do município. 
Todavia, o modelo estimado indica que esta variável possui um impacto negativo sobre a eficiência municipal.

Uma possível explicação para este resultado pode estar associada ao fato de a disponibilidade do recurso promovida não garantir que ele seja, corretamente, aplicado. Nesse sentido, o impacto negativo do PIB municipal pode estar associado à existência de um comportamento de captura na atividade de arrecadação própria, o que implica uma redução no bem-estar social da coletividade.

As estimativas referentes às variáveis demográficas mostraram que apenas a razão de dependência, que é a razão entre o segmento etário da população definido como economicamente dependente e o segmento potencialmente produtivo, teve impacto significativo sobre a eficiência municipal. Segundo Lubambo (2006), essa variável representa o grau de vulnerabilidade da população, o que justifica seu impacto negativo sobre a eficiência dos municípios.

As análises dos impactos das variáveis que compõem a dimensão social também foram condizentes com a expectativa teórica. Para a variável taxa de analfabetismo, o resultado demonstrou um impacto negativo e significativo, pois, quanto maior a taxa de alfabetização de uma população, mais eficientes serão os municípios na gestão dos recursos públicos, conforme apresentado por Afonso, Schuknecht e Tanzi (2006) e Ribeiro (2008). Para a variável renda familiar per capita, o resultado demonstrou um impacto positivo e significativo sobre a eficiência municipal. O efeito positivo da renda familiar pode ser explicado, pois, quanto maior for a renda familiar, maior a possibilidade de que a família busque no mercado os bens e serviços necessários para atender suas necessidades de bem-estar. Neste sentido, o acesso aos serviços privados oferecidos pelo mercado também desempenha um papel relevante na promoção do desenvolvimento socioeconômico.

\section{Conclusão}

Neste artigo procurou-se construir um indicador de eficiência municipal na promoção do desenvolvimento socioeconômico baseado na DEA. A partir desse indicador de eficiência buscou-se avaliar o impacto dos benefícios emitidos pela previdência social na eficiência municipal, controlando-se por outros determinantes com base na técnica de análise envoltória de dados em dois estágios.

Os resultados, obtidos na DEA primeiro estágio, demonstraram que os municípios das regiões menos desenvolvidas tendem a apresentar os piores indicadores de eficiência, comparativamente aos municípios das regiões com melhores níveis de desenvolvimento econômico e social. No segundo estágio, que consistiu na avaliação dos fatores determinantes da eficiência municipal, os resultados demonstraram que os benefícios da previdência social afetaram, positivamente, a eficiência na promoção do desenvolvimento socioeconômico entre os municípios de pequeno porte investigados, corroborando, assim, a hipótese daqueles segundo os quais a previdência social contribui para a melhoria do nível de bem-estar social nos níveis subnacionais. Nesse sentido, essa constatação pode ser considerada mais uma evidência da 
importância da previdência social para a população dos municípios de pequeno porte, principalmente para aqueles mais atrasados economicamente.

Uma explicação possível para este resultado seria o baixo dinamismo econômico desses municípios. A base econômica incipiente faz com que, nesses municípios, o mercado de trabalho seja pouco desenvolvido, sendo o setor público, em geral, uma das principais fontes de trabalho. Ainda em função de um mercado de trabalho pouco desenvolvido, muitos indivíduos em idade economicamente ativa são incentivados a migrar para outros municípios de maior porte em busca de emprego e renda, o que contribui para o aumento na proporção da população idosa. Diante dessa elevada proporção de idosos na população e do baixo nível de renda proveniente do mercado formal de trabalho, maior tende a ser a importância dos recursos provenientes dos benefícios pagos pela previdência social, que geralmente representam uma parcela relevante da renda familiar nesses municípios.

Por outro lado, é preciso ressaltar o argumento de que essa elevada participação da previdência social na renda das famílias poderia criar um problema de dependência familiar direta e indireta em torno daqueles que recebem os benefícios. De certa forma, o acesso aos recursos provenientes da previdência social poderia funcionar como um mecanismo de desincentivo à procura por trabalho formal.

Em relação aos outros determinantes da eficiência municipal, os resultados mostraram que, em sua maioria, os parâmetros são significativos e apresentam os sinais esperados. A redução na taxa de analfabetismo e o aumento na renda familiar per capita, por exemplo, contribuíram para melhoria do nível de eficiência municipal na geração de bemestar. Esses resultados corroboram o importante papel desempenhado pela escolaridade e pelo acesso à renda para o aumento da produtividade e para a geração de bem-estar no longo prazo.

Para as variáveis PIB municipal per capita, razão de dependência demográfica e a participação do PIB agropecuária no PIB municipal, os resultados demonstraram um impacto negativo sobre a eficiência municipal. Para as duas últimas variáveis os achados condizem com a expectativa teórica. No entanto, o sinal negativo do PIB per capita não confirmou a expectativa inicial de que uma base econômica mais desenvolvida contribuiria para o aumento da eficiência municipal. Nessa mesma direção, contrariamente ao que se esperava, o índice de desenvolvimento econômico tributário não apresentou nenhum impacto sobre a eficiência municipal.

Apesar de a metodologia empregada ter se mostrado relevante na análise desse tipo de investigação, principalmente por ter sido realizada uma investigação longitudinal com dados em painel, que oferece uma maior robustez aos resultados obtidos, este trabalho deve ser considerado exploratório e os indicadores tomados como proxies do comportamento real, no sentido em que os dados utilizados incluem erros prováveis de mensuração e omissão, o que pode levar a vieses nos resultados.

Ademais, há que se considerar que a eficiência municipal na geração de bem-estar social sofre influência de fatores historicamente construídos, tipo path-dependence, assim como 
de fatores institucionais de difícil mensuração e tangibilidade, que não puderam ser tratados neste artigo. Nesse sentido, a análise é conjuntural, dados os atributos de momento, específicos da ocorrência da coleta de dados.

Considerando esses e outros aspectos, constituem-se em agenda futura de pesquisa para este tema: a) a realização de estudos similares que adotem base de dados com maior amplitude regional, considerando outros estados ou até mesmo todo o território brasileiro, com possível controle de fatores institucionais e históricos, embora se reconheça que, apesar da melhoria das bases de dados disponíveis, seria uma tarefa ainda distante a realização de uma pesquisa longitudinal desse tipo considerando todos os municípios do país; b) incorporação de outros indicadores de insumos e produtos para investigação da eficiência municipal na geração de bem-estar, bem como outras proxies para os determinantes da eficiência municipal que não são consideradas neste estudo; e c) o uso de outras estratégias metodológicas para avaliação do impacto da previdência social sobre as condições socioeconômicas dos governos subnacionais.

\section{Referências}

AFONSO, António; SCHUKNECHT, Ludger; TANZI, Vito. Public sector efficiency: evidence for new EU member states and emerging markets. ECB Working Paper, n. 581, p. 1-49, 2006.

AFONSO, Luís E.; FERNANDES, Reynaldo. Uma estimativa dos aspectos distributivos da previdência social no Brasil. Revista Brasileira de Economia, v. 59, n. 3, p. 295-334, 2005.

BARRO, Robert J.; MACDONALD, Glenn M. Social security and consumer spending in an international cross section. Journal of Public Economics, v. 11, n. 3, p. 275-289, 1979.

BELLETTINI, Giorgio; CERONI, Carlotta B. Social security expenditure and economic growth: an empirical assessment. Research in Economics, v. 54, n. 3, p. 249-275, 2000.

CAETANO, Marcelo A. R. Determinantes da sustentabilidade e do custo previdenciário: aspectos conceituais e comparações internacionais. Brasília: Ipea, 2006. (Texto para discussão, n. 1226). Disponível em: <www.ipea.gov.br/sites/000/2/publicacoes/tds/td_1226.pdf>. Acesso em: 4 jan. 2013.

CARVALHO, Juan P. C. de. A previdência rural universalista e a sua relevância na economia dos municípios do Rio Grande do Norte. Dissertação (mestrado em ciências sociais) — Universidade Federal do Rio Grande do Norte, Rio Grande do Norte, 2010.

COSTANZI, Rogério N.; BARBOSA, Edvaldo D. A previdência social e a distribuição de renda intermunicipal. Estudos e Pesquisas da Secretaria de Políticas de Previdência Social 2003-2009, v. 11, n. 4, p. 94-111, 2009.

DELGADO, Guilherme; CARDOSO JUNIOR, José C. Principais resultados da pesquisa domiciliar sobre a previdência rural na região sul do Brasil: projeto avaliação socioeconômica da previdência social 
rural. Rio de Janeiro, Ipea: 2000. (Texto para discussão, n. 734). Disponível em: < http://agencia. ipea.gov.br/pub/td/2000/td_0734.pdf>. Acesso em: 20 dez. 2012.

DELGADO, Victor S. M.; MACHADO, Ana F. Eficiência das escolas públicas estaduais de Minas Gerais. Pesquisa e Planejamento Econômico, v. 37, n. 3, p. 427-464, 2007.

DIAMOND, Peter. A framework for social security analysis. Journal of Public Economics, v. 8, n. 3, p. 275-298, 1977.

FERREIRA, Carlos R.; SOUZA, Solange de C. I. de. Aposentadorias e pensões e desigualdade da renda: uma análise para o Brasil no período 1998-2003. Revista de Economia Contemporânea, v. 12, n. 1, p. 41-66, 2008.

FERREIRA, Marco A. M.; GONÇALVES, Rosiane M. L.; BRAGA, Marcelo J. Investigação do desempenho das cooperativas de crédito de Minas Gerais por meio da Análise Envoltória de Dados (DEA). Economia Aplicada, v. 11, n. 3, p. 425-445, 2007.

FIGUEIREDO, Ana T. L.; DINIZ, Clélio C. Distribuição regional da indústria mineira. Nova Economia, v. 10, n. 2, p. 39-69, 2000.

FINBRA. Finanças do Brasil. Secretaria do Tesouro Nacional, 2010. Disponível em: <www.stn. fazenda.gov.br>. Acesso em: 18 jan. 2012.

FIRJAN. Federação das Indústrias do Estado do Rio de Janeiro. Índice Firjan de desenvolvimento municipal, 2010. Disponível em:<www.firjan.org.br/IFDM>. Acesso em: 13 nov. 2011.

FJP. Fundação João Pinheiro. Índice mineiro de responsabilidade social. 2011. Disponível em: <www. datagerais.mg.gov.br/site/int_imrs.php>. Acesso em: 10 out. 2011.

FONSECA, Poty C.; FERREIRA, Marco A. M. Investigação dos níveis de eficiência na utilização de recursos no setor de saúde: uma análise das microrregiões de Minas Gerais. Saúde e Sociedade, v. 18, n. 2, p. 199-213, 2009.

FRANÇA, Álvaro S. Previdência social e a economia dos municípios. Brasília: Associação Nacional dos Auditores Fiscais da Receita Federal do Brasil (Anfip), 2004. Disponível em: <www.previdencia. gov.br/arquivos/office/3_081014-104850-324.pdf>. Acesso em: 17 jan. 2012.

FURTADO, Celso. Formação econômica do Brasil. São Paulo: Cia. Editora Nacional, 1967.

GOUDSWAARD, Kees; CAMINADA, Koen. The redistributive effect of public and private social programms: a cross-country empirical analysis. International Social Security Review, v. 63, n. 1, p. 1-19, 2010.

GREENE, William. Econometric analysis. Upper Saddle River, NJ: Prentice Hall, 2003.

GUPTA, Sanjeev; VERHOEVEN, Marijn. The efficiency of government expenditure: experiences from Africa. Journal of Policy Modeling, v. 23, n. 4, p. 433-467, 2001.

IBGE. Instituto Brasileiro de Geografia e Estatística. Censo demográfico. 2011. Disponível em: <www. censo2010.ibge.gov.br/resultados_do_censo2010.php>. Acesso em: 27 nov. 2011. 
LOPES, Luckas S.; TOYOSHIMA, Silvia H. Eficiência técnica municipal na gestão dos gastos com saúde e educação em Minas Gerais: seus impactos e determinantes. In: SEMINÁRIO SOBRE A ECONOMIA MINEIRA, 13., 2008, Diamantina. Anais... Diamantina: UFMG, 2008. p. 1-24.

LUBAMBO, Cátia W. Desempenho da gestão pública: que variáveis compõem a aprovação popular em pequenos municípios? Sociologias, v. 16, n. 8, p. 86-125, 2006.

MACIEL, Vladimir F.; PIZA, Caio C. de T.; PENOFF, Roberto N. Desigualdades regionais e bem-estar no Brasil: quão eficiente tem sido a atividade tributária dos estados para a sociedade? Planejamento e Políticas Públicas, v. 33, n. 2, p. 291-318, 2009.

MAGALHÃES, José C. Emancipação político-administrativa de municípios no Brasil. 2007. Disponível em: <http://desafios2.ipea.gov.br/agencia/images/stories/PDFs/livros/Capitulo1_30.pdf>. Acesso em: 20 abr. 2012.

MARQUES, Rui C.; SILVA, Duarte. Inferência estatística dos estimadores de eficiência obtidos com a técnica fronteira não paramétrica de DEA: uma metodologia de Bootstrap. Investigação Operacional, Lisboa, v. 26, n. 1, p. 89-110, 2006.

MENDES, Constantino C.; SOUSA, Maria da C. S. de. Estimando a demanda por serviços públicos nos municípios brasileiros. Revista Brasileira de Economia, v. 60, n. 3, p. 281-296, 2006.

MPS. Ministério da Previdência Social. Benefícios previdenciários superam FPM em 60\% dos municípios. Previdência em questão, n. 24, 2009. Disponível em: <www.previdenciasocial.gov.br/arquivos/office/3_090731-091327-591.pdf>. Acesso em: 17 jan. 2012.

MPS. Ministério da Previdência Social. Boletim Estatístico da Previdência Social. 2010a. Disponível em: <www.mpas.gov.br/conteudoDinamico.php?id=482>. Acesso em: 20 dez. 2011.

MPS. Ministério da Previdência Social. Estatísticas municipais 2000 a 2009. 2010b. Disponível em: <www.mpas.gov.br/conteudoDinamico.php?id=484>. Acesso em: 20 dez. 2011.

RAYP, Glenn; VAN DE SIJP, Nicolas. Measuring and explaining government efficiency in developing countries. Journal of Development Studies, v. 43, n. 2, p. 360-381, 2007.

REIS, Paulo R. da C.; SILVEIRA, Suely de F. R.; BRAGA, Marcelo J. Impactos dos benefícios previdenciários sobre o nível de bem-estar social nos municípios de Minas Gerais. In: ENCONTRO NACIONAL DOS PROGRAMAS DE PÓS-GRADUAÇÃO EM ADMINISTRAÇÃO, 35., 2011, Rio de Janeiro. Anais... Rio de Janeiro: Anpad, 2011. p. 1-17.

RIBEIRO, Márcio B. Desempenho e eficiência do gasto público: uma análise comparativa do Brasil em relação a um conjunto de países da América Latina. Rio de Janeiro: Ipea, 2008. (Texto para discussão, n. 1.368). Disponível em: <www.ipea.gov.br/sites/000/2/publicacoes/tds/td_1368. pdf>. Acesso em: 20 dez. 2012.

ROCHA, Sônia. Desigualdade regional e pobreza no Brasil: a evolução — 1981/95. Rio de Janeiro: Ipea, 1998. (Texto para discussão, n. 567). Disponível em: <www.ipea.gov.br/portal/images/stories/PDFs/TDs/td_0567.pdf>. Acesso em: 20 dez. 2012. 
SHIKIDA, Claudio D.; MILTON, Rodrigo S. de A.; ARAUJO JUNIOR, Ari F. Existe trade-off entre bem-estar e desigualdade? Um estudo de caso com municípios mineiros. Revista de Economia e Administração, v. 6, n. 1, p. 99-138, 2007.

WOOLDRIDGE, Jeffrey M. Econometric analysis of cross section and panel data. Cambridge, Mass.: MIT Press, 2002.

Paulo Ricardo da Costa Reis é doutorando em administração pelo Núcleo de Pós-Graduação em Administração da Universidade Federal da Bahia (NPGA/UFBA) e mestre em administração pela Universidade Federal de Viçosa (UFV).E-mail: paulo.reis@ufba.br.

Suely de Fátima Ramos Silveira é doutora em economia aplicada pela ESALq/Universidade de São Paulo (USP) e professora associada da Universidade Federal de Viçosa (UFV). E-mail: sramos@ufv.br.

Marcelo José Braga tem pós-doutorado pela University of California at Davis (UCD-EUA), é professor associado da Universidade Federal de Viçosa (UFV) e coordenador do Programa de Pós-Graduação em Economia Aplicada da UFV. E-mail: mjbraga@ufv.br. 